\title{
Novel Toll-like receptor-4 deficiency attenuates trastuzumab (Herceptin) induced cardiac injury in mice
}

Nasser Ghaly Yousif ${ }^{1,2^{*}}$ and Fadhil G Al-amran ${ }^{3}$

\begin{abstract}
Background: Cardiac inflammation and generation of oxidative stress are known to contribute to trastuzumab (herceptin) induced cardiac toxicity. Toll-like receptors (TLRs) are a part of the innate immune system and are involved in cardiac stress reactions. Since TLR4 might play a relevant role in cardiac inflammatory signaling, we investigated whether or not TLR4 is involved in trastuzumab induced cardiotoxicity.
\end{abstract}

Methods: Seven days after a single injection of herceptin (2 mg/kg; i.p.), left ventricular pressure volume loops were measured in HeN compotent $\left(\mathrm{TLR}_{4}^{+/+}\right)$and HeJ mutant $\left(\mathrm{TLR}^{-/}\right)$treated with trastuzumab and control mice. Immunofluorescent staining for monocyte infiltration and analyses of plasma by (ELISAs) for different chemokines including: MCP-1and tumor necrosis factor- $\alpha$ (TNF- $\alpha$ ), Western immunoblotting assay for ICAM-1, and used troponin I for cardiac injury marker.

Results: Trastuzumab injection resulted in an impairment of left ventricular function in TLR-4 competent (HeN), in contrast TLR4 $\%$ trastuzumab mice showed improved left ventricular function $\mathrm{EF} \%, \mathrm{CO} ; \mathrm{p}<0.05$, attenuation of mononuclear cell infiltration in TLR4 ${ }^{-1} ; \mathrm{p}<0.05$ vs.TLR-4 competent (HeN), reduced level of cytokines TNF- $\alpha$, MCP1 and ICAM-1 expression in TLR4 ${ }^{-1}$, marked reduction of myocardial troponin-I levels in TLR4-deficient mice. Data are presented as means $\pm \mathrm{SE} ; \mathrm{n}=8$ in each group $\mathrm{p}<0.05$ vs.TLR-4 competent (HeN).

Conclusions: Treatment with trastuzumab induces an inflammatory response that contributes to myocardial tissue TLR4 mediates chemokine expression (TNF- $\alpha$, MCP-1and ICAM-1), so in experimental animals TLR4 deficiency improves left ventricular function and attenuates pathophysiological key mechanisms in trastuzumab induced cardiomyopathy.

Keywords: Toll Like Receptor 4, cardiac-toxicity, Inflammation, trastuzumab

\section{Background}

The human epidermal growth factor receptor (HER) proteins regulate cell growth, survival, adhesion, migration, and differentiation functions that are amplified or weakened in cancer cells. In some cancers, notably some breast cancers, human epidermal growth factor receptor-2 (HER2) is over-expressed, and, among other effects, causes breast cells to reproduce uncontrollably [1]. Trastuzumab is a humanized monoclonal antibody that binds selectively to the HER2 protein. and has

\footnotetext{
* Correspondence: nasser.alemeerat@ucdenver.edu

'University of Colorado Denver, Department of Medicine and Surgery 12700 E 19th Avenue, Aurora, CO 80045, USA

Full list of author information is available at the end of the article
}

become a mainstay in the treatment of women with (HER2) overexpressing breast cancer and in the metastatic and adjuvant settings this increases the survival of people with cancer [2]. One of the significant complications of trastuzumab is its effect on the heart and association with cardiac dysfunction in 2-7\% of cases [3]. As a result, regular cardiac screening with either a MUGA (MUltiple Gated Acquisition) scan or echocardiography is commonly undertaken during the trastuzumab treatment period. Approximately $10 \%$ of patients are unable to tolerate this drug because of pre-existing heart problems; physicians are balancing the risk of recurrent cancer against the higher risk of death due to cardiac disease in this population. The risk of cardiomyopathy is

\section{() Biomed Central}


increased when trastuzumab is combined with anthracycline chemotherapy (which itself is associated with cardiac toxicity) $[4,5]$

Toll-like receptors (TLRs) have a central role in innate immunity and inflammation, at least nine types of human TLRs have recently been identified [6] Among the family of TLRs, TLR4 has been the focus of particular interest since its recognition as a receptor for lipopolysaccharide (LPS; endotoxin) $[7,8]$ It has been shown that active TLR4 led to expression of nuclear factor $-\kappa \mathrm{B}(\mathrm{NF}-\kappa \mathrm{B})$ controlled genes for proinflammatory cytokines that are required for activation of the immune response [9]

Previous study explained the Myocardial tissue TLR4 plays a major role in mediating myocardial injury following cold ischemia and reperfusion through up-regulation of MCP-1, (manuscript) [10]. Furthermore, increased TLR4 expression was observed in isolated cardiomyocytes from humans and animals with cardiomyopathies [11]. Growing evidence of a causal link between TLRs and the development of heart failure has been derived mostly from studies in knock-out mice supporting a relevant role of this receptor family. It had been shown that TLR4 can modulate LV hypertrophy, myocyte contractility, myocardial ischaemia reperfusion injury, and plays a role in inflammatory responses including septic shock syndrome [12]. It is notable that, cytokine release mediated by activation of the Toll- like receptors (TLRs ) is believed to be involved in the pathogenesis of doxorubicin induced cardiotoxicity $[13,14]$ and are probably also involved in the development of doxorubicin induced cardiomyopathy, as has been shown in TLR2- deficient mice [15]. Identification of TLR4 ligands and elucidation of the mechanisms of ligand-TLR4 interaction may lead to the development of novel approaches for prevention of myocardial injury associated with trastuzumab treatment.

\section{Aim of the study}

This study was done on mouse model to identify the effect of trastuzumab on TLR4 mutation in on the heart, leukocyte accumulation in the target area, MCP1, ICAM-1, and the role of these chemokines in myocardial injury and leukocyte accumulation after treatment with trastuzumab.

\section{Methods \\ Animals}

Male $\mathrm{C} 3 \mathrm{H} / \mathrm{HeJ}$ mice (which have a point mutation in TLR4, resulting in a complete loss of signaling function) and $\mathrm{C} 3 \mathrm{H} / \mathrm{HeN}$ (wild-type) mice, body weight 24-30 g, acclimatized in a quarantine room for 2 weeks, and their age range from 8 to 12 weeks. All experiments were approved by the Animal Care and Research Committee of the University of Colorado Denver, and this investigation conforms to the Guide for the Care and Use of Laboratory Animals (National Research Council, revised 1996). The animals divided in to 4 groups, control groups injected with normal saline and other groups treated with $2 \mathrm{mg} / \mathrm{kg}$ trastuzumab in a single injection intraperitoneal i.p.

\section{Pressure-volume loop and hemodynamic analysis}

Pressure-volume loop and hemodynamic analysis was only planned after 7 days of treated with trastuzumab, the mouse anesthetized with ketamin in dose of $50 \mathrm{mg} /$ $\mathrm{kg}$ injected intraperitoneal and when the mouse anaesthetized, it will be positioned over the heating pad in supine position and four limbs are taped, in a orientation that the hind limb in front of operating researcher. Neck was opened longitudinally and right common carotid artery exposed and freed, ligated distally and stay suture placed proximally, then small opening was made in artery and size $1 \mathrm{~F}$-micro tipped pressure transducer catheter (Millar Instruments, Houston, TX, USA) was inserted into the LV lumen via the right carotid artery for measurement of LV pressure, volume, function and related parameters. Then after about 20 minutes of data recording, the abdomen is opened by right sub costal incision to reach the inferior vena cava. To acutely change the cardiac preload, caval occlusion was produced over a 3-s period using a nonmetallic occluder applied to the IVC. The data were recorded as a series of pressure-volume loops.

$\mathrm{P}$ van software (Conductance Technologies, San Antonio, TX, and Millar, Houston, TX) was used to analyze all pressure-volume loop data. Regression analyses of multiple isochronal pressure-volume loop data were produced by IVC compression. From the baseline and IVC compression loops, comprehensive sets of hemodynamic parameters were calculated. All steady-state and caval occlusion pressure-volume loops were acquired with the computer data acquisition system. From these data we selected the following parameter: LV diameters were measured at end diastole (LVEDD) and end systole (LVESD), ejection fraction (EF), heart rate (HR), LV systolic pressure in the ends of both systole and diastole (LVESP, LVEDP), Cardiac Output (CO) and the maximum elasticity (Emax).

\section{Animal scarification}

Immediately after finishing the pressure volume loop measurement, the mouse was sacrificed, starting by injection of equal volume of thiopental and heparin intraperotonealy in doses ranging from $100 \mu \mathrm{l}$ to $200 \mu \mathrm{l}$ for each one, after giving good time for the animal to go into deep anesthesia, the mouse is positioned and taped and the chest is opened in flap like manner revealing the heart then a needle of the syringe is introduced into 
right ventricle to aspirate around $0.5 \mathrm{ml}$ of blood for plasma analysis. After that the heart is cut from the great vessels and mediastinum.

\section{Immunofluorescent Staining}

Myocardial sections (5 $\mu \mathrm{m}$ thick) were fixed in $4 \%$ paraformaldehyde, incubated with a rabbit polyclonal antibody against PMNs and macrophages, and then incubated with Cy3-tagged secondary goat anti-rabbit IgG (imaged on the red channel). Nuclei were stained with bis-benzimide (DAPI, imaged on the blue channel), and glycoproteins on cell surfaces with Alexa 488-tagged wheat germ agglutinin (imaged on the green channel). Microscopy was performed with a Leica DMRXA digital microscope (Leica Mikroskopie und Systeme GmbH, Wetzlar, Germany). Immunoflourecent antibodies were used to target the macrophages and neutrophils.

\section{Plasma for protein assay}

The collected blood from each mouse was centrifuged (in $10000 \mathrm{RPM}$, for 10 minutes at $4^{\circ} \mathrm{C}$ ) and the yielded plasma samples of each animal was subjected to protein assay using enzyme-linked immunosorbent assays (ELISAs) for different chemokines including: MCP-1, tumor necrosis factor- $\alpha$ (TNF- $\alpha$ ), and troponin I.

\section{Western immunoblotting assay}

Myocardial tissue was homogenized with a rotor-stator homogenizer and treated in PBS containing 0.5\% Triton X-100 and a protease inhibitor cocktail. Size fraction of crude protein $(20 \mu \mathrm{g})$ was performed by electrophoresis. After transfer, the membrane was incubated in PBS 5\% nonfat dry milk to block nonspecific binding. The membrane was then incubated for 60 minutes with an antibody against ICAM-1, or TLR4 at 1:1000 to $1: 2000$ dilutions with PBS containing 0.05\% Tween 20 and 5\% dry milk. After thorough washes, the membrane was treated with peroxidase-labeled secondary antibody (1:5000 dilutions with phosphate-buffered saline containing $0.05 \%$ Tween 20 and 5\% dry milk) for 45 minutes. Protein bands were developed using enhanced chemiluminescence technique. Densitometry was performed using a computerized densitometer (Molecular Dynamics, Sunnyvale, CA).

\section{Statistical analysis}

Statistical analysis was performed using the one-way ANOVA test with a significance of $\mathrm{p}<0.05$.

\section{Results}

\section{TLR4 mutation improves LV function}

Selected average parameters from pressure-volume loop study in the $\mathrm{C} 3 \mathrm{H} / \mathrm{HeJ}$ (TLR4 $/^{-}$) and $\mathrm{C} 3 \mathrm{H} / \mathrm{HeN}$ groups were shown in table-1, the $\mathrm{C} 3 \mathrm{H} / \mathrm{HeJ}\left(\mathrm{TLR} 4^{-} /^{-}\right.$) group has significantly better LV function and ventricular elasticity than the wild $\mathrm{HeN}$ group in form of $\mathrm{EF} \%$, and Cardiac Output (CO).

\section{TLR4 $\%$ attenuated mononuclear cells infiltration}

After seven days of a single injection trastuzumab TLR4-competent (HeN-wild type) hearts exhibited marked increase in mononuclear cell infiltration compared with TLR4 /- (HeJ mutant) hearts which is demonstrated by immunostaining as in Figure 1.

\section{Reduced level of cytokines TNF-a, MCP-1 and ICAM-1 expression in TLR4 $\%$}

To characterize the cardiac inflammatory response due to the trastuzumab injection, we determined cardiac cytokines, expression of TNF- $\alpha$ protein, MCP-1and ICAM-1. led to an increased expression both of them in $\mathrm{WT}(\mathrm{C} 3 \mathrm{H} / \mathrm{HeN})$ mice compared to $\mathrm{TLR} 4^{-1-}(\mathrm{HeJ}$ mutant $)(P<0.05)$ Figure 2.

\section{Marked reduction of myocardial troponin-I levels in TLR4- deficient mice}

The level of the troponin-I as cardiac injury marker show significant reduction in $\mathrm{C} 3 \mathrm{H} / \mathrm{HeJ}$ strains after seven days a single dose injection of trastuzumab, and this reflected that the cardiac injury is more in wild type, as shown in Figure 3.

Table 1 Selected average parameters from pressure-volume loop study in the $\mathrm{C} 3 \mathrm{H} / \mathrm{HeN}$ and $\mathrm{C} 3 \mathrm{H} / \mathrm{HeJ} \mathrm{groups}$

\begin{tabular}{cccccc}
\hline Variables & & HeN & & HeJ & After Tras. \\
& Before Tras. & After Tras. & Before Tras. & Aftue \\
\hline Heart rate (bpm) & $449.67 \pm 2.29$ & $392.44 \pm 16.47$ & $452 \pm 16$ & $448 \pm 31$ & $<0.05$ \\
End-systolic Volume (uL) & $13.42 \pm 0.25$ & $45.23 \pm 0.42$ & $14.04 \pm 0.38$ & $21.28 \pm 0.60$ & $<0.05$ \\
End-diastolic Volume(uL) & $35.25 \pm 0.36$ & $63.77 \pm 0.51$ & $34.90 \pm 0.55$ & $41.40 \pm 0.54$ & $<0.05$ \\
End-systolic pressure(mmHg) & $123.8 \pm 0.47$ & $179.35 \pm 3.40$ & $122.3 \pm 1.03$ & $139.22 \pm 1.04$ & $<0.05$ \\
End-diastolic pressure(mmHg) & $8.2 \pm 0.58$ & $97.40 \pm 3.53$ & $7.97 \pm 0.09$ & $15.28 \pm 0.17$ & $<0.05$ \\
Ejection Fraction (\%) & $61.91 \pm 8.9$ & $29.06 \pm 1.05$ & $63.14 \pm 2.17$ & $52.17 \pm 2.56$ & $<0.05$ \\
Cardiac Output (ml/min) & $10.44 \pm 4.54$ & $5.03 \pm 0.57$ & $11.01 \pm 0.30$ & $9.84 \pm 0.28$ & $<0.05$ \\
\hline
\end{tabular}

*Data are expressed as mean $\pm S E M ; n=8$ in each group $P$ value $<0.05$. 

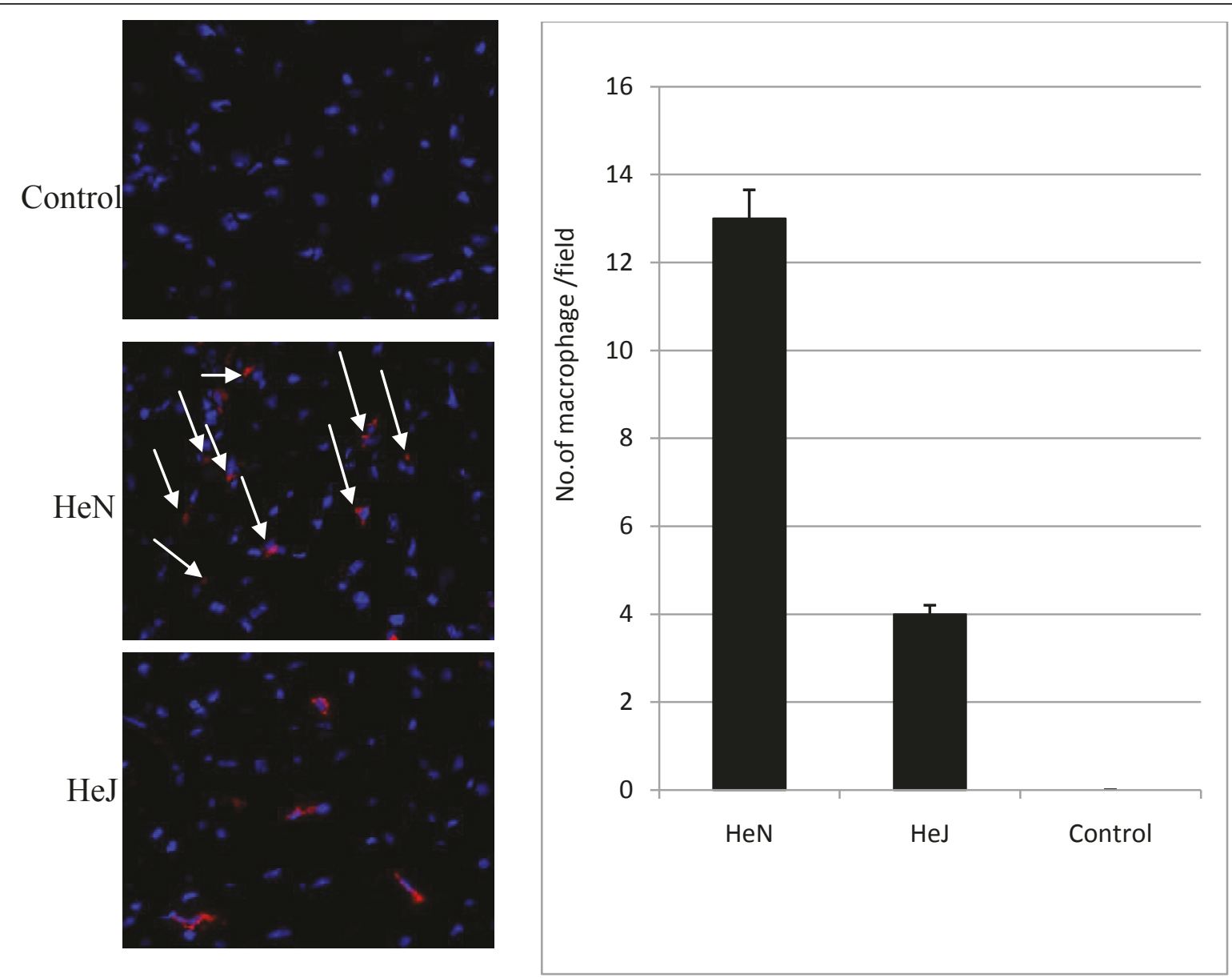

Figure 1 Immunofluorescent Staining of the myocardial cells for demonstrated mononuclear cells infiltration. Attenuated of infiltration mononuclear cells (white lines) in HeJ, data are presented as means $\pm \mathrm{SE} ; \mathrm{n}=8$ in each group, $\mathrm{p}<0.05$ vs. TLR- 4 competent (HeN)

\section{Discussion}

The antitumor functions of trastuzumab are associated with its ability to modulate signaling through the HER$2 /$ neu receptor as well as initiate antibody-dependent cell-mediated cytotoxicity (ADCC) [15]. Recent studies suggest that trastuzumab disrupts HER2/HER3 interactions, leading to downregulation of AKT signaling, which results in decreased cell proliferation [16-18]. At any stage, the use of trastuzumab reduces recurrence by about $50 \%$ and increases overall survival by about $30 \%$ [19-21] and reduction in the risk for death by about $44 \%(P<.0001$, hazard ratio $[\mathrm{HR}]=0.56)[22]$.

In approximately $4 \%$ of patients with trastuzumab therapy are associated with severe congestive heart failure, and most of the cardiac toxicity seen with treatment is limited to asymptomatic decreases in the left ventricular ejection fraction (LVEF); however [23].

In the present study, we tested the hypotheses that TLR4 mediates mononuclear infiltration and chemokine expression that response to underlying trastuzumab treatment. We found that TLR4-competent mice treated with trastuzumab display severe systolic and diastolic LV dysfunction, resulting in impaired cardiac output as measured by the assessment of pressure - volume loops, while in TLR4 $\%$ cardiac output was improved as a result of enhanced systolic and diastolic performance, and reduced mononuclear infiltration with significantly lower levels of TNF- $\alpha$, MCP-1 and ICAM-1. These result of correspond to myocardium injury after global ischemia and reperfusion led to TNF- expression and other cytokines [24], and is under the control by myocardial TLR4 [25], TNF- may serve as an intermediate in TLR4-mediated myocardial, including IL-8 and MCP1. In myocardiac regional ischemia and reperfusion (I/R) demonstrate a critical role of TLR4 in myocardial chemokines response [26].

The John Cha [27] and his group studies show that the TLR4 signaling is involved in the myocardial inflammatory response after global ischemia/reperfusion and that TLR4 signaling contributes to cardiac dysfunction 


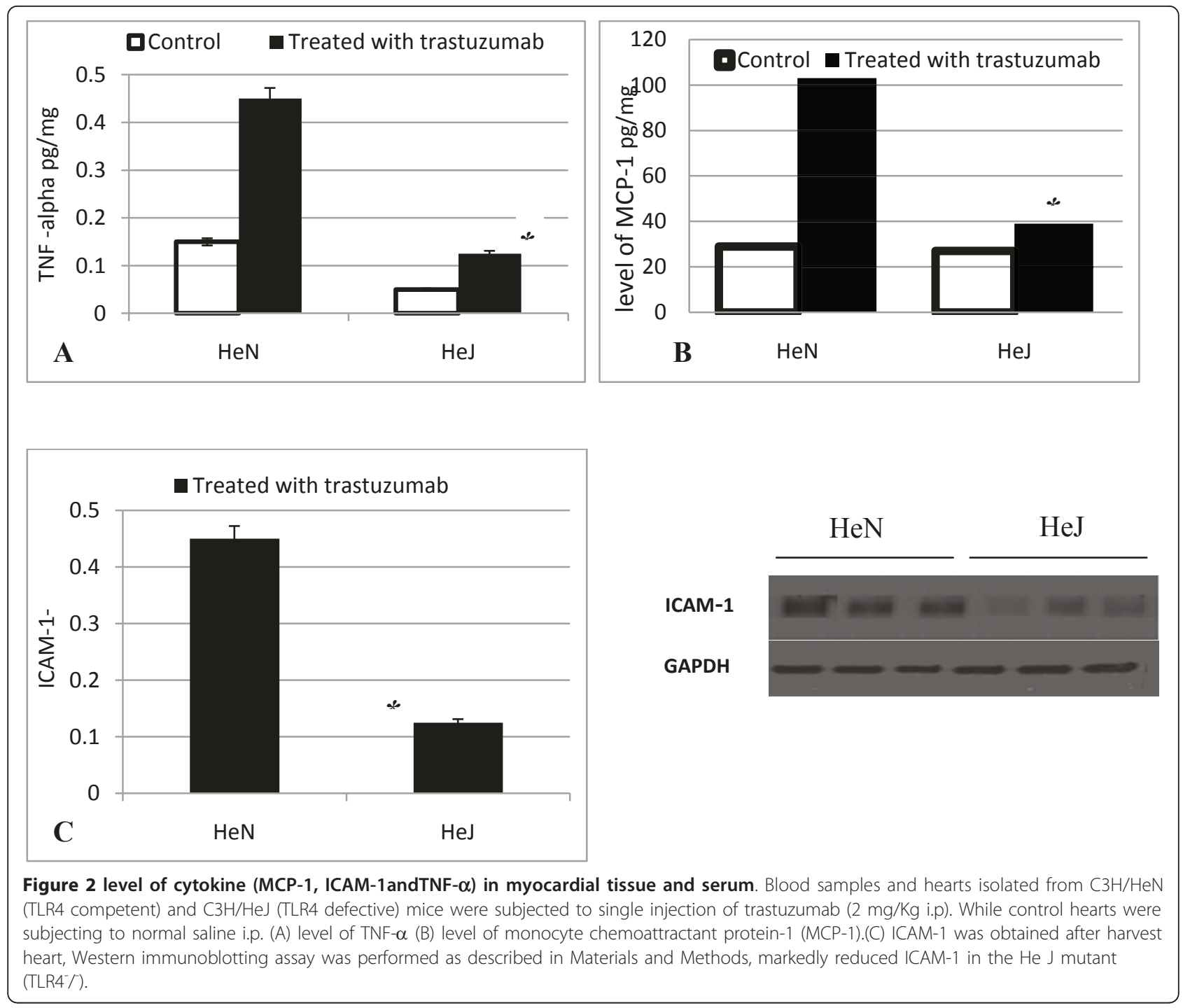

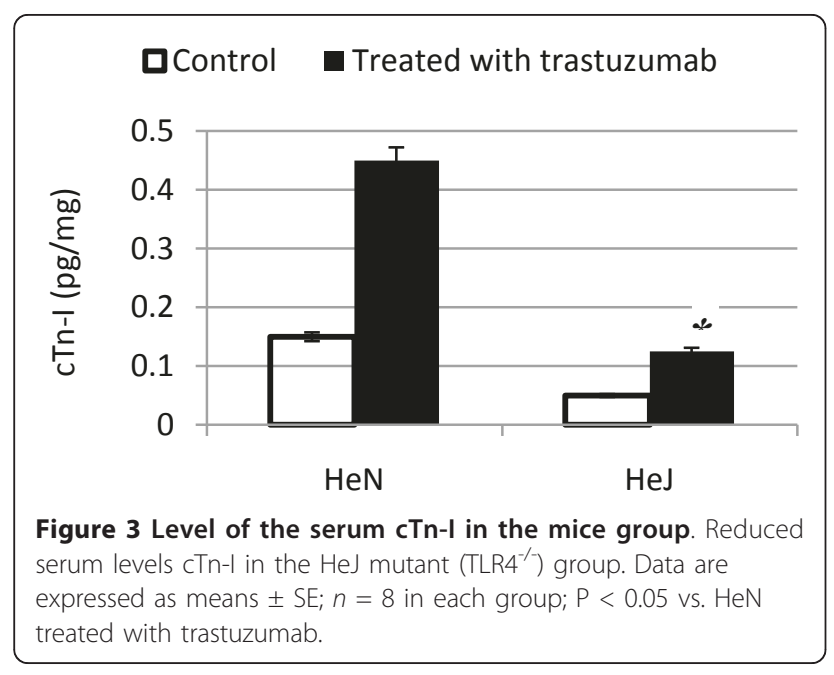

after global ischemia/reperfusion through its influence on myocardial production of TNF- $\alpha$ and IL-1 peptides. The Kaczorowski and colleagues [28] in which their data demonstrate that TLR4 signaling is central to both the systemic and intragraft inflammatory responses that occur after cold $I / R$ in the setting of organ transplantation.

In our earlier study we found that the Myocardial injury after global cold ischemia and perfusion was evaluated by serum cardiac troponin-I (cTn-I) as cardiac marker injury that was decreased levels in HeJ, p $<0.05$ vs. TLR4 competent $(\mathrm{HeN})[29,30]$ also we found the same sequel in the present study the serum levels of cTn-I in the HeJ mutant $\left(\mathrm{TLR}^{-1-}\right.$ ) was reduced.

According to our knowlage no study was done that link between the TLR4 and trastuzumab treatment, so our data demonstrate for the first time a relevant role of 
TLR4 in the development myocardial injury following used trastuzumab under experimental conditions. Further studies using therapeutic interventions such as pharmacological TLR4 inhibition are required.

\section{Conclusions}

This study demonstrates that treated with trastuzumab induces an inflammatory response that contributes to myocardial tissue TLR4 as mediates chemokine expression (TNF- $\alpha$, MCP-1and ICAM-1), so in experimental animals TLR4 deficiency improves left ventricular function and attenuates pathophysiological key mechanisms in herciptin-induced cardiomyopathy.

\section{Acknowledgements}

This study was funded by a grant from the NIH. Also we thanks Lihoa Li, Dr. Janan Al-baghdadi, Dr. Aal M. Sadiq for their help in prepares this manuscript.

\section{Author details}

${ }^{1}$ University of Colorado Denver, Department of Medicine and Surgery 12700 E 19th Avenue, Aurora, CO 80045, USA. ${ }^{2}$ Asadder Teaching Hospital, Al-najaf, Iraq. ${ }^{3}$ Kufa University, Surgical Dept -College of Medicine, Najaf, Iraq.

\section{Authors' contributions}

NGY carried out the plasma for protein assay, Western immunoblotting assay, participated in the design of the study and performed the statistical analysis, participated in the sequence alignment and drafted the manuscript. FGA carried out the Pressure-volume loop and hemodynamic analysis and participated in the design of the study. All authors read and approved the final manuscript.

\section{Competing interests}

The authors declare that they have no competing interests.

Received: 23 November 2010 Accepted: 14 October 2011 Published: 14 October 2011

\section{References}

1. Hudis CA: Trastuzumab-mechanism of action and use in clinical practice. N Engl J Med 2007, 357(1):39-51.

2. Tripathy Debu: Cardiac side effects of trastuzumab: lessons learned from targeting cancer pathways. Nature Reviews Clinical Oncology 2007, , 4: 220-221.

3. Chien AJ, Rugo HS: University of California San Francisco, Helen Diller Family Comprehensive Cancer Center, San Francisco. Expert Opin Drug Saf 2010, 9(2):335-346.

4. Seidman A, et al: Cardiac Dysfunction in the Trastuzumab Clinical Trials Experience. Journal of Clinical Oncology 2002, 20(5):1215-1221.

5. Garratt AN, Ozcelik C, Birchmeier C: ErbB2 pathways in heart and neural diseases. Trends Cardiovasc Med 2003, 13:80-86.

6. Medzhitov R: Toll-like receptors and innate immunity. Nat Rev Immunol 2001, 1:135-145.

7. Poltorak A, He X, Smirnova I, Liu MY, Van Huffel C, Du X, et al: Defective LPS signaling in $\mathrm{C} 3 \mathrm{H} / \mathrm{HeJ}$ and $\mathrm{C} 57 \mathrm{BL} / 10 \mathrm{ScCr}$ mice: mutations in Tlr4 gene. Science 1998, 282:2085-2088.

8. Hoshino K, Takeuchi O, Kawai T, Sanjo H, Ogawa T, Takeda Y, et al: Cutting edge: Toll-like receptor 4 (TLR4)-deficient mice are hyporesponsive to lipopolysaccharide-evidence for TLR4 as the Lps gene product. J Immunol 1999, 162:3749-3752.

9. Medzhitov R, Preston-Hurlburt P, Janeway CA Jr: A human homologue of the Drosophila toll protein signals activation of adaptive immunity. Nature 1997, 388:394-397.

10. Kaczorowski JDavid, Nakao Atsunori, Mollen PKevin, Vallabhaneni Raghuveer, Sugimoto Ryujiro, Kohmoto Junichi, Tobita Kimimasa, Zuckerbraun SBrian, McCurry RKenneth, Murase Noriko,
Billiar RTimothy: Toll-ike Receptor 4 Mediates the Early Inflammatory Response After Cold Ischemia/Reperfusion. Transplantation 2007, 84(10):1279-1287.

11. Oyama J, Blais C Jr, Liu X, Pu M, Kobzik L, Kelly RA, Bourcier T: Reduced myocardial ischemia-reperfusion injury in toll-like receptor 4-deficient mice. Circulation 2004, 109:784-789.

12. Akira S, Takeda K: Toll-like receptor signalling. Nat Rev Immunol 2004, 4(7):499-511.

13. Liu L, Zhang X, Qian B, Min X, Gao X, Li C, et al: Over-expression of heat shock protein 27 atte nuates doxorubicin-induced cardiac dysfunction in mice. Eur J Heart Fail 2007.

14. Minotti G, Menna P, Salvatorelli E, Cairo G, Gianni L: Anthracyclines: molecular advances and pharmacologic developments in antitumor activity and cardiotoxicity. Pharmacol Rev 2004, 56(2):185-229.

15. Methe H, Kim JO, Kofler S, Weis M, Nabauer M, Koglin J: Expansion of circulating Toll-like receptor 4-positive monocytes in patients acute coronary syndrome. Circulation 2005, 111(20):2654-61.

16. Ross JS, Slodkowska EA, Symmans WF, Pusztai L, Ravdin PM, Hortobagyi GN: The HER-2 receptor and breast cancer: ten years of targeted anti-HER-2 therapy and personalized medicine. Oncologist 2009, 14:320-368.

17. Junttila TT, Akita RW, Parsons K, et al: Ligand-independent HER2/HER3/ $\mathrm{PI} 3 \mathrm{~K}$ complex is disrupted by trastuzumab and is effectively inhibited by the PI3K inhibitor GDC-0941. Cancer Cell 2009, 15:429-440.

18. Spector NL, Blackwell KL: Understanding the mechanisms behind trastuzumab therapy for human epidermal growth factor receptor 2positive breast cancer. J Clin Oncol 2009, 27:5838-5847.

19. Katsumi $Y$, Kuwahara $Y$, Tamura S, et al: Trastuzumab activates allogeneic or autologous antibody-dependent cellular cytotoxicity against malignant rhabdoid tumor cells and interleukin-2 augments the cytotoxicity. Clin Cancer Res 2008, 14:1192-1199.

20. Musolino A, Naldi N, Bortesi B, et al: Immunoglobulin $G$ fragment $C$ receptor polymorphisms and clinical efficacy of trastuzumab-based therapy in patients with HER-2/neu-positive metastatic breast cancer. J Clin Oncol 2008, 26:1789-1796.

21. Bedard PL, Piccart-Gebhart MJ: Current paradigms for the use of HER2targeted therapy in early-stage breast cancer. Clin Breast Cancer 2008, 8(suppl 4):S157-165.

22. Dawood S, Broglio K, Buzdar AU, Hortobagyi GN, Giordano SH: Prognosis of women with metastatic breast cancer by HER2 status and trastuzumab treatment: an institutional-based review. J Clin Oncol 2010, 28:92-98.

23. De Azambuja E, Bedard PL, Suter T, Piccart-Gebhart M: Cardiac toxicity with anti-HER-2 therapies: what have we learned so far? Target Oncol 2009, 4:77-88.

24. Shames BD, Barton HH, Reznikov LL, Cairns CB, Banerjee A, Harken AH, Meng $X$ : Ischemia alone is sufficient to induce TNF- mRNA and peptide in the myocardium. Shock 2002, 17:114-119.

25. Cha J, Wang Z, Ao L, Zou N, Dinarello CA, Banerjee A, Fullerton DA, Meng $X$ : Cytokines link Toll-like receptor 4 signaling to cardiac dysfunction after global myocardial ischemia. Ann Thorac Surg 2008, 85:1678-1685.

26. Chong AJ, Shimamoto A, Hampton CR, Takayama H, Spring DJ, Rothnie CL, Yada M, Pohlman TH, Verrier ED: Toll-like receptor 4 mediates ischemia/ reperfusion injury of the heart. J Thorac Cardiovasc Surg 2004, 128:170-179.

27. Cha John, Wang Zhiping, Ao Lihua, Zou Ning, Dinarello ACharles, Banerjee Anirban, Fullerton ADavid, Meng Xianzhong: Cytokines Link TollLike receptor 4 signaling to cardiac dysfunction after global myocardial ischemia. Ann Thorac Surg 2008, 85:1678-85.

28. Kaczorowski JDavid, Nakao Atsunori, Mollen PKevin, Vallabhaneni Raghuveer, Sugimoto Ryujiro, Kohmoto Junichi, Tobita Kimimasa, Zuckerbraun SBrian, McCurry RKenneth, Murase Noriko, Billiar RTimothy: Toll-like Receptor 4 Mediates the Early Inflammatory Response After Cold Ischemia/Reperfusion. Transplantation 2007, 84(10):1279-1287.

29. Yousif NG, Ao L, Li J, Aly A, Austin E, Fullerton DA, Meng X: Myocardial Tissue TLR4 Plays a Major Role in Mediating Myocardial Injury Following Cold Ischemia and Reperfusion Through Up-regulation Of MCP-1. ASC 2011 Abstract, Quick shot, Transplant \& Immunology (Transplant/Immunology)

30. Al-amran FG, Yousif NG, Meng XM: A TLR4-MCP-1-macrophage IL-18 Cascade plays major role in Myocardial Injury and Cardiac Dysfunction 
after Permanent Ischemia. 6th Annual Academic Surgical Congress 2011 Abstract, schemia \& Cardiopulmonary By. pass (Cardiothoracic).

Pre-publication history

The pre-publication history for this paper can be accessed here: http://www.biomedcentral.com/1471-2261/11/62/prepub

doi:10.1186/1471-2261-11-62

Cite this article as: Yousif and Al-amran: Novel Toll-like receptor-4

deficiency attenuates trastuzumab (Herceptin) induced cardiac injury in mice. BMC Cardiovascular Disorders 2011 11:62.

Submit your next manuscript to BioMed Central and take full advantage of:

- Convenient online submission

- Thorough peer review

- No space constraints or color figure charges

- Immediate publication on acceptance

- Inclusion in PubMed, CAS, Scopus and Google Scholar

- Research which is freely available for redistribution

Submit your manuscript at www.biomedcentral.com/submit 